\title{
Phenolic composition and antioxidant potential of different solvent extracts of the endemic Origanum elongatum (Bonnet) Emberger\& Maire
}

\author{
Imane Tagnaout * , Hannou Zerkani, Sanae Amine, Kamal Fadili, Nadia Benhlima, Amal Bouzoubaa and \\ Touriya Zair *
}

\begin{abstract}
Department of Chemistry, Bioactive Molecules and Environment, Moulay Ismail University, Faculty of sciences Meknes, CP 50000, Morocco, BP 11201, Zitoune, Meknes-Morocco
\end{abstract}

\begin{abstract}
Plants of the Lamiaceae family are widely used for medicinal, cosmetic and culinary purposes. Phenolic compounds such as flavonoids and tannins are the main constituents of these plants; they have a proven multidirectional biological activity. Polyphenols have exceptional antioxidant potential, and they can intervene in the prevention of many health disorders. This work aims to study the composition and antioxidant power of phenolic compounds from crude extracts and fractions of Origanum elongatum leaves. This specie was subjected to phytochemical study through precipitation, turbidity and coloring reactions to highlight their secondary metabolites qualitative composition. Polyphenolic extraction was made by Soxhlet using two solvents: methanol $70 \%$, ethanol 70\%. Then, methanol's crude was fractionated with solvents having escalating polarity; ethyl acetate, n-butanol. The polyphenols and flavonoids contents were spectrophotometrically estimated using Folin-Ciocalteau and Aluminum Trichloride methods. The antioxidant power of crude and fractionated extracts was evaluated by diphenyl-picryl-hydrazyl $\left(\mathrm{DPPH}^{\bullet}\right)$ and iron (FRAP) tests. The screening tests showed the existence of polyphenols, mucilages, sterols and triterpenes, oses and holosides. The highest yield of extraction is obtained by $70 \%$ methanol, with an average of $32.29 \%$. Quantitative assays indicated that the hydroethanolic extract and the ethyl acetate fraction possessed high amount of polyphenols and flavonoids compared with other fractions and subsequently exhibited a marked scavenging activity on DPPH radical $\left(\mathrm{IC}_{50}=0,085 \pm 0,002\right.$ and $0,112 \pm 0,003 \mathrm{mg} / \mathrm{ml}$, respectively) and high reductive ability on ferric ion assay with $\mathrm{IC}_{50}=0,181 \pm 0,004 \mathrm{mg} / \mathrm{ml}$, $0,291 \pm 0,005 \mathrm{mg} / \mathrm{ml}$, respectively.
\end{abstract}

Keywords: Origanum elongatum (Bonnet) Emberger\& Maire, polyphenols contents, flavonoïdes, DPPH, FRAP.

\section{Introduction}

Since ancient times, fresh and dried medicinal plants and their derived products have been widely used for flavoring. In the last decades, they have also been the subject of numbers researches on natural antioxidants ${ }^{1-3}$. Plus, many scientific studies proved the potential of medicinal plants as natural antioxidants. Among these plants, Origanum species are used as spices.

Furthermore, they possess various biological activities whose potentials have been revealed by several scientific studies exposed to the public ${ }^{4,5}$; indeed some species are available in almost all public markets. The genus Origanum belongs to the family of Lamiaceae, called "Oregano" in English. It is divided into 39 species, distributed in the Mediterranean, Euro-Siberian and Iran-Turanian regions ${ }^{6-8}$. Because of his multiple therapeutic and culinary properties, Oregano has been used as a remedy for thousands of years. The ancient Greek and Roman empires applied leaves for the treatment of skin lesions, and as antiseptics, as well as for other diseases such as asthma, diarrhea and indigestion ${ }^{9}$. In Greece, an infusion of oregano is still used as a popular remedy against colds and stomach ache. The Mediterranean flora in general and Moroccan in particular gathers many species of plants which are little or still not studied but have relevant pharmacological properties. The Lamiaceae family contains about 236 genera and more than 6000 species; these plants are commonly used to treat several disorders ${ }^{10}$, as they also present a tremendous ecological and economic interest. Throughout Morocco, the species of oregano are known locally as "Zaatar" and "Zwi" in Berber. An aqueous infusion of Zaatar is traditionally employed to cure dysentery, colitis, respiratory illness, gastric acidity and gastrointestinal diseases ${ }^{11}$. 
According to Ietswaart, (1980) ${ }^{12}$, Origanum elongatum (Bonnet) Emberger and Maire is an endemic perennial that exists in the Rif, mountain of Tazekka and mountain of Bouyablane. It grows in schistose soils between 400 and $1500 \mathrm{~m}$ of altitude. This specie gets ornamental interest due to the abundance and the lightness of the inflorescences and staggering of flowering. In the earlier times, essential oil of $O$.elongatum was hand-distilled and sold commercially as the essence of thyme Rif. In Moroccan folk medicine, the infusion of $O$. elongatum is used in liver diseases. Besides this specie is extremely attractive to honeybees. Several scientific studies and research have elucidated the biological activities of the essential oil of Origanum elongatum (Bonnet) Emb. \& Maire such as antifungal activity ${ }^{13}$, acaricide activity ${ }^{14}$, antibacterial and antiviral ${ }^{15}$. However, according to our knowledge, no previous studies have been conducted regarding the phytochemical and biological study of extracts of Origanum elongatum (Bonnet) Emberger\& Maire. In this perspective, the present paper is intended to complete the previous research in the field aiming to study: the phytochemical characterization of the polyphenols compounds and the in vitro antioxidant activities of extracts of Origanum elongatum (Bonnet) Emberger\& Maire.

\section{Experimental}

\subsection{Chemicals}

Bismuth(III) nitrate, 1-(+)-tartaric acid, potassium iodide, mercury(II) chloride, sodium acetate, isoamyl alcohol, ferric chloride, magnesium chips, isoamyl alcohol, dipotassium hydrogen phosphate, potassium dihydrogen phosphate, sodium carbonate, butylated hydroxytoluene, butylated hydroxyanisole, gallic acid and quercetin were used as standards, aluminum chloride $\left(\mathrm{AlCl}_{3}\right)$, DPPH, Folin-Ciocalteu's phenol reagent and trichloroacetic acid (TCA) were acquired from Sigma-Aldrich. For acetic anhydride, sulfuric acid, formaldehyde, hydrochloric acid, and solvents used were of analytical grade were purchased from Merck Co. (Darmstadt, Germany).

\subsection{Plant material}

Plant material was collected in August 2016, from the mountain of Bouyablane. It was identified at the Rabat Scientific Institute. The leaves were dried at room temperature away from light and finely ground using an electric grinder.

\subsection{Methods}

\subsubsection{Phytochemical analysis of plant material}

Various chemical tests were performed with a phytochemical screening. It is a qualitative test based on color reactions and/or precipitation.

Characterization tests of different chemical groups were performed according to experimental protocols by Joshi el al. (2013) ${ }^{16}$, and Bruneton (2009) ${ }^{17}$.
The extracts were obtained by extraction with the following solvents: petroleum ether, methanol, ethanol, chloroform and distilled water.

The phytochemical screening is also based on the use of several reagents. The research of alkaloids was done by precipitation reactions with the general reagents (Mayer and Dragendorff), while the reaction by ferric perchloride (2\%) was used for the detection of polyphenols. Flavonoids were detected by the cyanidin reaction while the reaction of Stiasny was used to detect the gallic and catechin tannins. Confirming the inexistence of saponins was conducted by measuring the foam index, whereas the reaction of Liebermann Buchard allowed detecting the sterols and triterpenes. Concentrated sulfuric acid and saturated alcohol with thymol have revealed the monosaccharides and holosides; absolute ethanol is used to characterize the mucilages.

\subsubsection{Extraction of polyphenols of O.elongatum (Bonnet) Emb.\&Maire}

A quantity of 30 grams of ground material from a dry pulverized sample was extracted within aqueous methanol $(70 \%)$ and aqueous ethanol $(70 \%)$ for $6 \mathrm{~h}$ using the Soxhlet method. After filtration, the aqueous alcohol solution $(70 \%)$ obtained was evaporate to dry the filtrate by using the rotary evaporator until a solid residue was obtained and then recovered by a volume of hot distilled water.

The hydromethanolic extract was suspended in distilled water and was subjected to successive extractions (splitting) of liquid-liquid using organic solvents with increasing polarity (ethyl acetate and n-butanol). Then all fractions were dried by using a rotary evaporator at $60^{\circ} \mathrm{C}$ and preserved at $4^{\circ} \mathrm{C}$.

\subsubsection{Estimation of polyphenols contents}

The presence of polyphenols was determined by the Folin-Ciocalteu method, described by Dehpour et al., (2009) ${ }^{18}$.

In volumetric flask $(100 \mathrm{ml}), 1,5 \mathrm{ml}$ of FolinCiocalteu reagent (10\%) was added to the plant extracts, mixed and incubated for $6 \mathrm{~min}$ at room temperature before the addition of $1,5 \mathrm{ml}$ of $\mathrm{Na}_{2} \mathrm{CO}_{3}$ solution $(75 \mathrm{~g} / \mathrm{l})$. The solutions were adjusted with distilled water to a final volume of $100 \mathrm{ml}$. After $2 \mathrm{~h}$ of incubation at room temperature, the absorbance was measured at $760 \mathrm{~nm}$. The calibration curve is performed by gallic acid with a concentration of $50 \mu \mathrm{g} / \mathrm{ml}(5 \mathrm{mg} / 100 \mathrm{ml})$. Concentrations of phenolic compounds of each extract were calculated from the equation of the regression of the calibration range with gallic acid $(y=0,095 \times+0,003)$. The results were expressed as milligrams of the gallic acid equivalent of per gram of extract (mg GAE/g of extract). However, the polyphenol contents were calculated according to the following formula (1): 
$\mathrm{T}=\frac{(\mathrm{C} \times \mathrm{V})}{\mathrm{M}} \times \mathrm{D}$

$\mathrm{C}$ : Concentration measured by the calibration curve. $\mathrm{V}$ : Volume of the overall sample (ml). D: Dilution factor. M: Weight of the extract plant $(\mathrm{g})$.

\subsubsection{Estimation of flavonoids contents}

The total flavonoids content of O.elongatum (Bonnet) Emb.\&Maire was estimated by the method of chloride $\left(\mathrm{AlCl}_{3}\right)$ aluminum, using the Protocol of Atanasova \& Ribarova, (2009) ${ }^{19}$, with modifications.

In volumetric flask $(50 \mathrm{ml}), 0,1 \mathrm{ml}$ of chloride aluminum $(10 \%)$ was mixed with oregano extract, after $5 \mathrm{~min}, 20 \mathrm{ml}$ of distilled water is added. The solution was adjusted to $50 \mathrm{ml}$ with absolute methanol, shaken immediately and then kept two hours in the dark for 2 hours. The absorbance of each solution was measured at $433 \mathrm{~nm}$. Under the same conditions, the standard solution of the quercetin is prepared with a concentration equal to $0,1 \mathrm{mg} / \mathrm{ml}$ $(25 \mathrm{mg} / 250 \mathrm{ml})$. Flavonoids concentration of each extract were calculated from the equation of the regression of the calibration range with quercetin $(y=0,073 x-0,081)$. However, the flavonoid contents were calculated according to the following formula (2):

$\mathrm{T}=\frac{(\mathrm{C} \times \mathrm{V})}{\mathrm{M}} \times \mathrm{D}$

$\mathrm{C}$ : Concentration measured by the calibration curve. $\mathrm{V}$ : Volume of the overall sample $(\mathrm{ml})$. D: Dilution factor. M: Weight of the extract $(\mathrm{g})$

\subsubsection{Antioxidant activity assays}

\subsubsection{DPPH radical scavenging assay}

The scavenging activity of the free radical, 2,2-diphenyl-1-picrylhydrazyl (DPPH) was determined by the method described by Nikhat and al., (2009) ${ }^{20}$. The extracts and fractions of oregano $(1,4 \mathrm{mg} / \mathrm{ml})$ were solubilized in absolute ethanol. This solution known as mother solution will be diluted to obtain the following concentrations: $(0,07 ; 0,14 ; 0,28$; $0,42 ; 0,56 ; 0,7 ; 0,84 ; 0,98 ; 1,12 ; 1,26 ; 1,4 \mathrm{mg} / \mathrm{ml})$. $200 \mu \mathrm{l}$ of each extract at different concentrations was mixed with $2,8 \mathrm{ml}$ of ethanolic DPPH $\left(6,10^{-5} \mathrm{~mol} / \mathrm{l}\right)$ previously prepared. Antioxidant standards solutions Butylated hydroxytoluene (BHT) and butylated hydroxyanisole (BHA) are also prepared under the same conditions. The control consists of $2,8 \mathrm{ml} \mathrm{DPPH}$ solution and $200 \mu \mathrm{l}$ ethanol absolute. After $30 \mathrm{~min}$ incubation in the darkroom, the absorbance was read at a wavelength of $517 \mathrm{~nm}$. Radical scavenging activity against DPPH was expressed as a percentage of inhibition, and this was calculated according to the following formula:

$A A \%=\frac{\mathrm{A}(\text { control })-\mathrm{A}(\text { sample })}{\mathrm{A}(\text { control })} \times 100$

AA\%: Percentage of inhibition activity; A (control): absorbance of the solution containing only DPPH radical solution and $\mathrm{A}$ (sample): absorbance of sample solution to be tested in the presence of DPPH.

Using the percentage of inhibition values, a doseresponse curve was plotted, from which the $\mathrm{IC}_{50}$ value was extrapolated. The antioxidant activity was expressed as $\mathrm{IC}_{50}$ value which was the concentration $(\mathrm{mg} / \mathrm{ml})$ that inhibited the DPPH radicals by $50 \%$.

\subsubsection{Ferric reducing power assay}

The reducing ability of the sample crude extracts and fractions was measured by the transformation of $\mathrm{Fe}^{3+}$ to $\mathrm{Fe}^{2+}$ following the method described by ZovkoKoncic ${ }^{21}$. The extracts and fractions of oregano $(1,4 \mathrm{mg} / \mathrm{ml})$ were solubilized in distilled water. This solution known as mother solution will be diluted to obtain the following concentrations: $(0,07 ; 0,14 ; 0,28$; $0,42 ; 0,56 ; 0,7 ; 0,84 ; 0,98 ; 1,12 ; 1,26 ; 1,4 \mathrm{mg} / \mathrm{ml})$. In test tubes, $1 \mathrm{~m}$ of the diluted extract was added to $2,5 \mathrm{ml}$ of phosphate buffer and $2.5 \mathrm{ml}$ of potassium ferricyanide $(1 \%)$. The mixture was incubated at $50^{\circ} \mathrm{C}$ for $20 \mathrm{~min}, 2,5 \mathrm{ml}$ of trichloroacetic acid (10\%) was added to the mixture. After centrifuged at $3000 \mathrm{rpm}$ for $10 \mathrm{~min}, 2.5 \mathrm{ml}$ of the upper layer of the mixture was mixed with $2,5 \mathrm{ml}$ distilled water and $0,5 \mathrm{ml}$ of $\mathrm{FeCl}_{3}$ solution $(0,1 \%)$. The absorbance was measured at $700 \mathrm{~nm}$. Butylated hydroxytoluene (BHT) and butylated hydroxyanisole (BHA) were used as standards. Increased absorbance of the reaction mixture indicated increased reducing power.

\subsection{Statistical Analysis}

The statistical analysis was performed by OriginPro 8.5 software. All data were expressed as means \pm SD of triplicate measurements and are compared by oneway ANOVA test, followed by the Tukey test. P values less than or equal to 0.05 are considered statistically significant.

\section{Results and discussion}

\subsection{Phytochemical composition}

Phytochemical tests were performed on various extracts prepared from $O$. elongatum leaves and results are reported in Table 1.

The results of the characterization tests of the metabolites highlight the presence of polyphenols, mucilages, sterols and triterpenes, oses and holosides, plus the absence of alkaloids, saponosides, free and combined anthraquinones.

This specie has a remarkable richness in polyphenols, especially flavonoids. They are present in the aqueous extract in three forms; anthocyanins, free flavonoids (flavones) and leucoanthocyanins. Flavonoids possess anti-inflammatory, antiallergic, antioxidant properties, plus they are called vitamin $\mathrm{P}$ because they maintain a normal vascular permeability ${ }^{22,23}$. On the one hand, they are recognized for their antihepatotoxic ${ }^{24}$, antiulcer 25 , enzyme inhibitors activities ${ }^{26}$. 
Table 1. Results of the phytochemical screening of O.elongatum.

\begin{tabular}{|c|c|}
\hline Phytoconstituent & Origanum elongatum \\
\hline Alkaloids & --- \\
\hline Tannins & +++ \\
\hline Catechins Tanins & --- \\
\hline Gallics Tanins & +++ \\
\hline Free flavonoïds & +++ \\
\hline Anthocyanins & +++ \\
\hline Leucoanthocyanes & +++ \\
\hline Anthraquinones Free & - \\
\hline O-glycosides & - \\
\hline Anthraquinones combined & - \\
\hline Sterols and triterpenes & +++ \\
\hline Saponosids & - \\
\hline Oses and holosides & ++ \\
\hline Mucilages & ++ \\
\hline
\end{tabular}

High concentration (+++); moderate concentration (++); low concentration (+); absence (-).

For that reason, the Stiasny reagent test was carried out, and no precipitate was detected, which confirms the absence of catechetical tannins. However, the presence of gallic tannins was confirmed by the apparition of a blue-black hue. Mostly gallic tannins are recommended for the treatment of bronchitis and cough. Moreover, many studies have shown their antidiarrheal ${ }^{27}$, antibacterial and antifungal properties ${ }^{28}$. Besides, they have high antioxidant activity and the ability to scavenge free radicals ${ }^{29}$. The chemical diversity of this Oregano affirms its pharmacological properties and its frequent use by the Moroccan population.

The findings converge with those of Oualili et al., (2018) ${ }^{30}$, who have demonstrated the presence of gallic tannins, sterols, and flavonoids in leaves of O.elongatum. Plus, they did not detect any presence of alkaloids and saponins.

In comparison with other species, our results are in good agreement with those noted for $O$. compactum, researchers have found the presence of the phenols, flavonoids, leucoanthocyanins, sterols and terpenoids ${ }^{31}$. For $O$. majorana, various phytochemical tests revealed the existence of terpenoids, flavonoids, tannins, and the absence of alkaloids in ethanol extract ${ }^{32}$.

\subsection{Extraction yields}

It is apparent through observing the extraction yields summarized in Table 2, that the yields of crude extracts vary according to the polarity of the extraction solvents in which methanol has produced the best extraction yield compared to ethanol. For the fractionated extracts, the residual aqueous fraction recorded the highest yield $(47,45 \%)$, followed by the n-butanol fraction $(23,41 \%)$ while ethyl acetate had the lowest yield $(21,95 \%)$. The extraction yield mainly depends on the solvent polarity, $\mathrm{pH}$, temperature, extraction time and composition of the plant studied.

\subsection{Estimation of polyphenols and flavonoids contents}

\subsubsection{Polyphenols content (PC)}

The polyphenols compounds presented in the crude and fractioned extracts $\left(F_{0}, F_{1}, F_{2}, F_{3}, F_{4}\right)$ were expressed as $\mathrm{mg}$ of gallic acid equivalents per gram extract (mg GAE/g).

The polyphenols contents of the crude extracts and solvent fractions obtained from studied Oregano are shown in Table 2. From this Table, it was evident that the crude extracts and fractions are very rich in phenolic compounds. The polyphenolic content varied from $516,79 \pm 14,27$ to $19,45 \pm 0,19 \mathrm{mg} \mathrm{GAE} / \mathrm{g}$ extract. The obtained results of all extracts were found significantly different $(p<0,05)$ from each other. The highest polyphenols content was recorded in the hydroethanolic crude extract with a value of $516,79 \pm 14,27 \mathrm{mg}$ GAE$/ \mathrm{g}$ extract. For the fractionated extracts, ethyl acetate fraction showed the highest polyphenols content $(239,04 \pm 0,69 \mathrm{mg} \mathrm{GAE} / \mathrm{g}$ the fraction), whereas the polyphenols contents of the residual aqueous fraction were much smaller $(19,45 \pm 0,19 \mathrm{mg} \mathrm{GAE} / \mathrm{g}$ the fraction). However, the hydromethanolic extract results are lower than those obtained by Douhri et al., (2014) ${ }^{33}$ for O.elongatum methanolic extract $(83,61 \pm 0.19 \mathrm{mg} \mathrm{GAE} / \mathrm{g}$ extract $)$. Also Bouyahya et al., (2017) ${ }^{34}$, noticed highest 
polyphenols content for O.compactum methanol extract $(153,27 \pm 0,68 \mathrm{mg} \mathrm{GAE} / \mathrm{g}$ extract $)$.

The high yields of polyphenols extraction can be explained by the solubility of other compounds such as proteins and carbohydrates in methanol than in ethanol and ethyl acetate ${ }^{35}$. Indeed, the ethanol and ethyl acetate were the most excellent solvents in extracting phenolic compounds from the extracts.

\subsubsection{Flavonoids content (FC)}

The contents of flavonoids were calculated as $\mathrm{mg}$ quercetin equivalents per $\mathrm{mg}$ per gram extract (mg QE/g).

The flavonoids compounds, as noted in Table 2 in $O$. elongatum crude extracts and fractions were recorded ranging from 26,54 $\pm 0,19 \mathrm{mg}$ to $1,72 \pm 0,08 \mathrm{mg} / \mathrm{g}$ of extract. The flavonoids contents of all extracts are significantly different $(\mathrm{p}<0,05)$ from each other. The hydroethanolic crude extract showed the highest flavonoids content $(26,54 \pm 0,19 \mathrm{mg} \mathrm{QE} / \mathrm{g}$ of extract), whereas the hydromethanolic crude extract was the smaller in flavonoids $(1,72 \pm 0,08 \mathrm{~g} \mathrm{QE} / \mathrm{g}$ of the fraction).

Among the three fractions, ethyl acetate fraction was the higher one $(23,71 \pm 0,32 \mathrm{mg} \mathrm{QE} / \mathrm{g}$ of the fraction), while the residual aqueous fraction was the lowest in total phenolic $(2,46 \pm 0,11 \mathrm{~g} \mathrm{QE} / \mathrm{g}$ of the fraction).

The hydromethanolic extract results are much lower than those reported by Douhri et al., (2014) ${ }^{33}$ from the methanolic extract of O.elongatum whose gave $10,85 \pm 0,05 \mathrm{mg} \mathrm{QE} / \mathrm{g}$ extract.

El Babili et al., (2011) ${ }^{36}$, also reported much higher flavonoids content in ethyl acetate fraction $(54,7 \pm 1,8 \mathrm{mg} \mathrm{QE} / \mathrm{g}$ of extract) for Origanum compactum. According to Scholz \&Rimpler (1989) ${ }^{37}$, ethyl acetate has a significant selectivity in the extraction of phenolic compounds. Moreover, Wei and al., (2010) ${ }^{38}$ have reported that the phenolic compounds tend to accumulate in the medium-polar fraction such as ethyl acetate due it medium polarity.

Phenolic compounds such as flavonoids occur in many plant-based foods, as they have provided significant antioxidant activity ${ }^{39}$. Also, phenolic are involved in plant defence mechanism against ultraviolet radiation, infections or aggression by pathogens. Therefore, the presence of these compounds in the studied extracts could contribute to its antioxidant activity.

Table 2. Total phenolic and flavonoid contents and extraction yield of $O$. elongatum.

\begin{tabular}{|c|c|c|c|}
\hline Plant extracts & Extraction yield (\%) & $\begin{array}{c}\text { Total phenolic } \\
\text { (mg GAE/ g of extract })\end{array}$ & $\begin{array}{c}\text { Flavonoids } \\
\text { (mg QE/g of extract) }\end{array}$ \\
\hline Hydroethanolic extract $\left(\mathrm{F}_{0}\right)$ & $24,65 \pm 0,18$ & $516,79 \pm 14,27$ & $26,54 \pm 0,19$ \\
\hline hydromethanolic extract $\left(\mathrm{F}_{1}\right)$ & $32,29 \pm 0,12$ & $44,98 \pm 0,19$ & $1,72 \pm 0,08$ \\
\hline Ethyl acetate fraction $\left(\mathrm{F}_{2}\right)$ & $21,95 \pm 0,02$ & $239,04 \pm 0,69$ & $23,71 \pm 0,32$ \\
\hline Butanol fraction $\left(\mathrm{F}_{3}\right)$ & $23,41 \pm 0,05$ & $64,27 \pm 0,49$ & $2,46 \pm 0,41$ \\
\hline Residual aqueous fraction $\left(\mathrm{F}_{4}\right)$ & $47,45 \pm 0,03$ & $19,45 \pm 0,11$ \\
\hline \multicolumn{2}{|r|}{ Results with different superscripts are significantly different from each other $(\mathrm{P}<0.05)$} \\
\hline
\end{tabular}

\subsection{DPPH radical scavenging assay}

Figure 1 illustrates the scavenging activities of plant extracts, fractions and the standards (BHA, BHT) on DPPH radical. The obtained results showed that the crude extracts and fractions have a great ability to trap the DPPH·radical.

At a concentration of $0,14 \mathrm{mg} / \mathrm{ml}$, the hydroethanolic extract and ethyl acetate fraction had higher inhibition percentages than BHA $(55,70 \%)$ and BHT $(20,83 \%)$. The scavenging activity of the extracts increased in a concentration-dependent manner. The percentage of inhibition increased with increasing concentration of extracts until it reaches a plateau. This phenomenon can be explained by the saturation of the electron shells of the DPPH radical.

From the analysis of $\mathrm{IC}_{50}$ values (Table 3 ), The DPPH radical scavenging activity of all our extracts are significantly different from each other $(\mathrm{P}<0.05)$, the hydroethanolic extract revealed the highest antiradical activity $\left(\mathrm{IC}_{50}=0,085 \pm 0,002 \mathrm{mg} / \mathrm{ml}\right)$ followed by the ethyl acetate fraction with an $\mathrm{IC}_{50}$ about $0,112 \pm 0,003 \mathrm{mg} / \mathrm{ml}$ compared to BHA $\left(\mathrm{IC}_{50}=0,121 \pm 0,003 \mathrm{mg} / \mathrm{ml}\right)$ and BHT $\left(\mathrm{IC}_{50}=0,489 \pm 0,002 \mathrm{mg} / \mathrm{ml}\right)$. However, the residual aqueous fraction had the lowest ability. The difference in the antioxidant activity between the extracts essentially depends on total phenolic flavonoids, and other aromatic compounds contents present. An extract is considered to be active against free radicals if $\mathrm{IC}_{50}<5 \mathrm{mg} / \mathrm{ml}^{40}$. All our extracts and fractions have $\mathrm{IC}_{50}$ values less than $5 \mathrm{mg} / \mathrm{ml}$. Therefore all the extracts for the solvents used are a possible good source of antioxidants.

The work of Oualili et al., (2018) ${ }^{30}$ revealed that the antioxidant activity of organic extract of $O$. elongatum was higher than that recorded in the presence of $\delta$-tocopherol. 
Also, Bouyahya et al., (2017) ${ }^{34}$ confirmed that the methanolic and ethanolic extracts of Origanum compactum contain significant antioxidant potential in the scavenging of the DPPH. Several studies have highlighted the antioxidant activity of oregano ${ }^{41,42}$.

Gutiérrez-Grijalva et al. ${ }^{43}$, reported that the antioxidant activity of oregano is due to a variety of compounds as there is a significant correlation between antioxidant activity and flavonoids content. Baranauskaite et al., (2017) ${ }^{4}$ showed that the antioxidant activity of extracts of the three different species of Oregano $(O$. onites L., $O$. vulgare L. and $O$. vulgares $\mathrm{sp}$. hirtum) depends on the species due to the different amounts of rosmarinic acid, which is in agreement with Madsen's (1996) ${ }^{43}$ report.
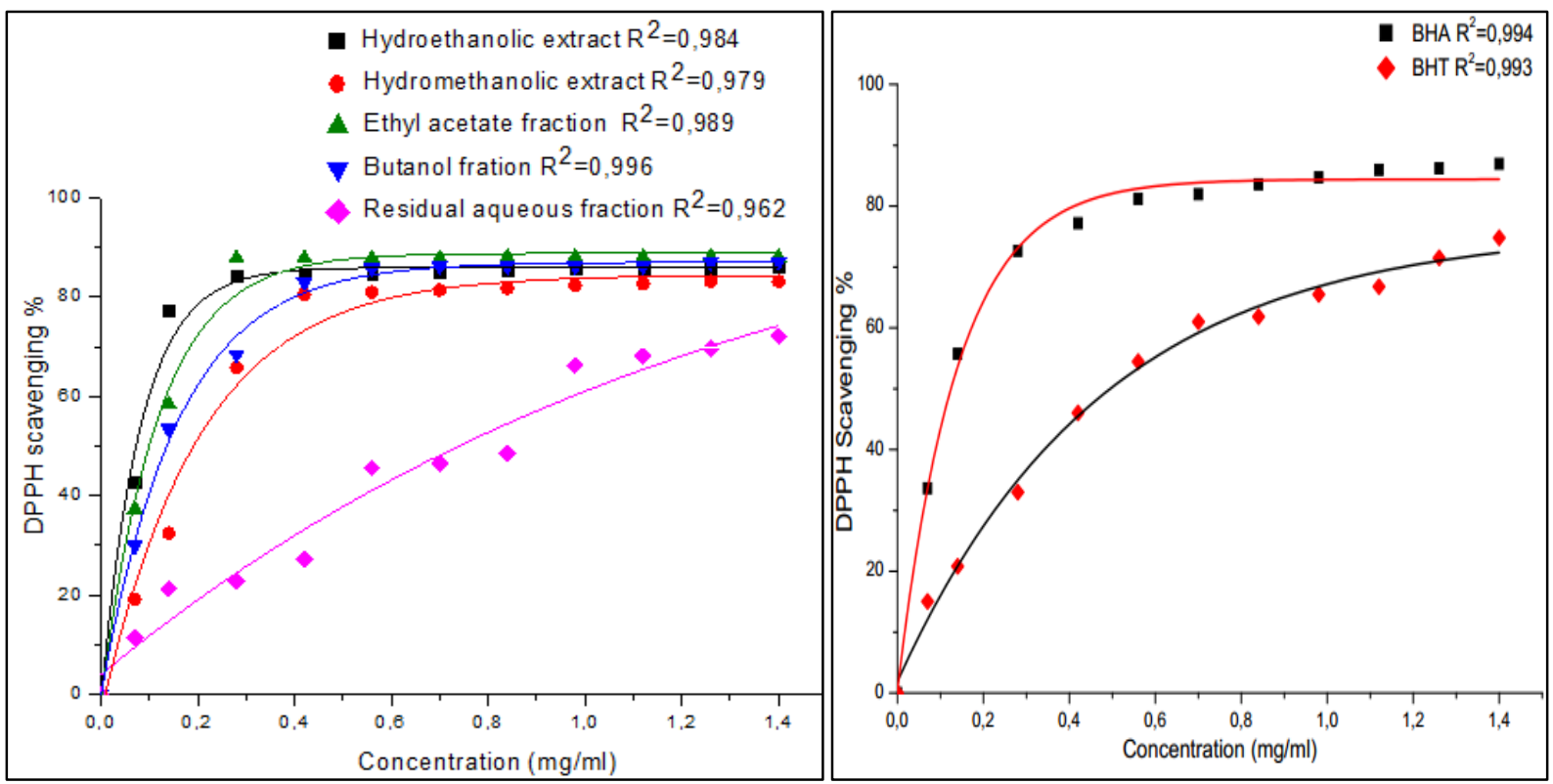

Figure 1. Scavenging effect of O. elongatum (Bonnet) Emb. \& Maire crude extracts and its fractions and positive controls (BHT, BHA) at varying concentrations on DPPH·

Table 3. Antioxidant effect $\left(\mathrm{IC}_{50}\right)$ of crude extracts and fractions by DPPH and (FRAP) methods.

\begin{tabular}{|c|c|c|}
\hline Extracts & DPPH IC $\mathbf{5 0}(\mathbf{m g} / \mathbf{m l})$ & FRAP EC $_{\mathbf{5 0}}(\mathbf{m g} / \mathbf{m l})$ \\
\hline Hydroethanolic extract & $0,085 \pm 0,002$ & $0,181 \pm 0,004$ \\
\hline Hydromethanolic extract & $0,218 \pm 0,003$ & $0,347 \pm 0,004$ \\
\hline Ethyl acetate fraction & $0,112 \pm 0,003$ & $0,291 \pm 0,005$ \\
\hline Butanol fraction & $0,139 \pm 0,002$ & $0,556 \pm 0,006$ \\
\hline ResidualAqueous fraction & $0,856 \pm 0,003$ & $0,414 \pm 0,007$ \\
\hline BHA & $0,121 \pm 0,003$ & $0,545 \pm 0,015$ \\
\hline BHT & $0,489 \pm 0,002$ & $0,094 \pm 0,005$ \\
\hline
\end{tabular}

Results with different superscripts are significantly different from each other $(\mathrm{P}<0.05)$

\subsection{Reducing power assay}

Metal ions had a vital role in the human body, especially in cellular biochemical and physiological processes, however in some cases when their mechanism of action is not controlled, the metal ions can cause several metabolic disorders (hypertension, rheumatism, heart disease, etc.). Flavonoids, due to their specific chemical structure, can easily chelate metal ions by creating inactive complex compounds ${ }^{44}$.

In FRAP assay, the presence of reducers in extracts is manifested by the reduction of the yellow $\mathrm{Fe}^{+3} /$ ferric cyanide complex to the greenish-blue iron form by the donation of an electron. The increase in absorbance at $700 \mathrm{~nm}$ reflects an increase in reduction potential.

Figure 2 presents the antioxidant activity of crude extracts and fractions of $O$. elongatum when compared to the positive controls (BHA and BHT). At concentrations ranging from 0.28 to $1.4 \mathrm{mg} / \mathrm{ml}$, it can be observed that all the extracts and fractions possess reducing potential.

In order to compare the reducing ability of the extracts and fractions of $O$. elongatum got by this method, we calculate $\mathrm{EC}_{50}$, which is defined as the concentration necessary to reduce $50 \%$ of the iron (Table 3 ). The results obtained were found significantly different 
$(\mathrm{p}<0,05)$, from which $\mathrm{EC}_{50}$ values are varying from $0,181 \pm 0,004$ to $0,556 \pm 0,006 \mathrm{mg} / \mathrm{ml}$. The best activity was noted by the hydroethanolic extract with an $\mathrm{EC}_{50}$ of $0,181 \pm 0,004 \mathrm{mg} / \mathrm{ml}$.

Among the fractions, ethyl acetate fraction was the most active $\left(\mathrm{EC}_{50}=0,291 \pm 0,005 \mathrm{mg} / \mathrm{ml}\right)$ followed by the aqueous fraction $\left(\mathrm{EC}_{50}=0,347 \pm 0,004 \mathrm{mg} / \mathrm{ml}\right)$. On the other hand, the butanol fraction showed a relatively moderate power.
Comparing these results with those of positive controls (BHA, BHT), the hydroethanolic extract and ethyl acetate fraction have a remarkable reducing power, on the one hand, it is higher than that of BHA $\left(\mathrm{EC}_{50}=0,545 \pm 0,015 \mathrm{mg} / \mathrm{ml}\right)$, but it is still significantly less than that of BHT with an $\mathrm{EC}_{50}$ of $0,094 \pm 0,005 \mathrm{mg} / \mathrm{ml}$. The reducing power of Origanum elongatum is probably due to the presence of hydroxyl groups in phenolic compounds that can be used as electron donors. Hence, antioxidants are considered as oxidant reducers and scavengers ${ }^{45}$.
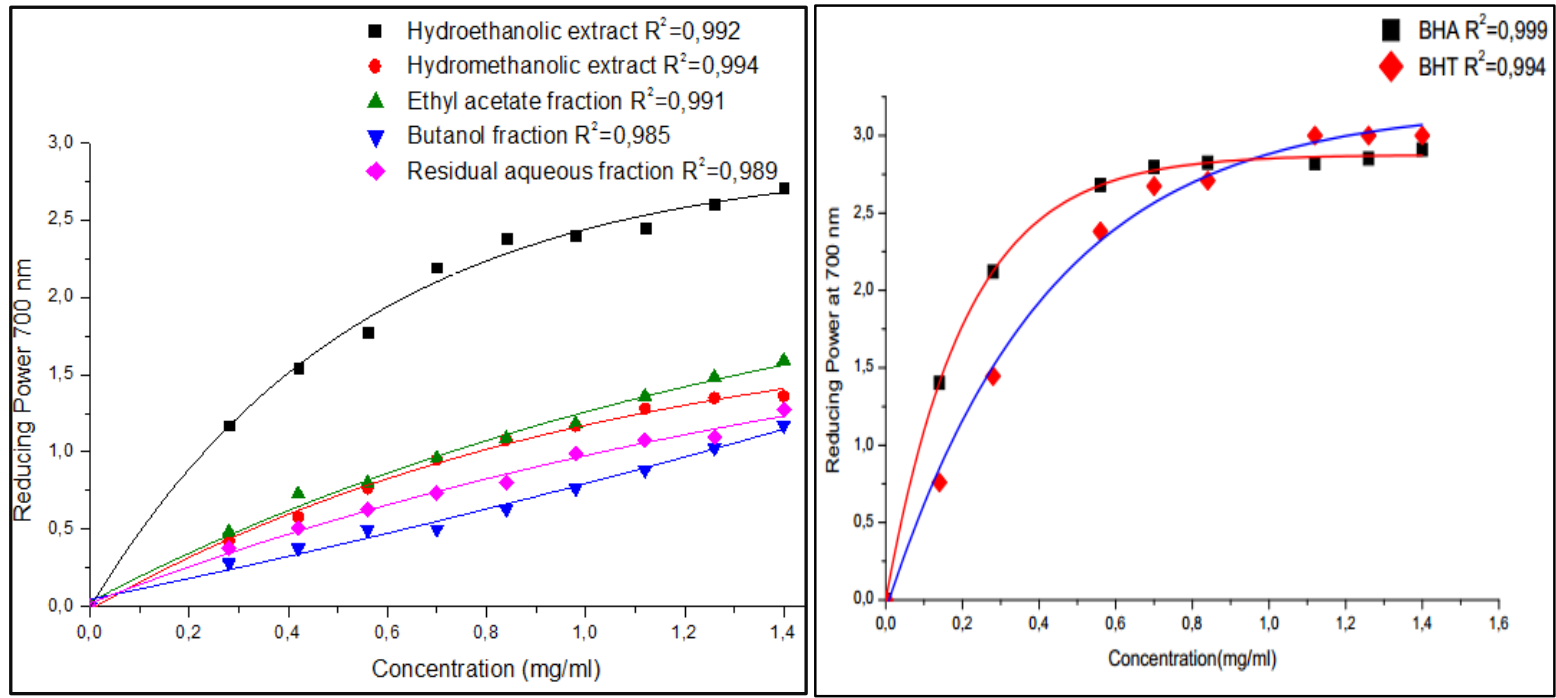

Figure 2. Reducing power of crude extracts and its fractions of O. elongatum (Bonnet) Emb. \& Maire and positive controls (BHT, BHA) at different concentrations

\section{Conclusion}

To our knowledge, this study is the first to present the characterization of phenolic compounds and antioxidant activity by DPPH and FRAP methods of O.elongatum, endemic of Morocco. All crude and fractionated extracts contained significant amounts of phenolic and flavonoids, especially hydroethanolic extract and ethyl acetate fraction indicated the highest amounts. Also, they exhibited exciting antiradical activity and an excellent ability to reduce iron. As such, there is a perfect correlation between phenolic contents and antioxidant activity. These results indicate the presence of certain active compounds that can be further investigated for use as food additives to substitute synthetic additives and preservatives in cosmetic and pharmaceutical formulations.

\section{References}

1- P.R. Venskutonis, Food additives: The dilemma of synthetic or natural. Acta Alimentaria,2004, $33,1,1-5$.

2- M. A. Shah, S. J. D. Bosco, S. A. Mir, Plant extracts as natural antioxidants in meat and meat products, Meat Sci, 2014, 98, 21-33.

3- I. L. Elisha, J. P. Dzoyem, L. J. McGaw, F. S. Botha, J. N. Eloff, The anti-arthritic, antiinflammatory, antioxidant activity and relationships with total phenolics and total flavonoids of nine South African plants used traditionally to treat arthritis, BMC Complement Altern Med, 2016, 16(1), 1-10.

4- J. Baranauskaite, A. Kubiliene, M. Marksa, V. Petrikaite, K. Vitkevičius, A. Baranauskas, J. Bernatoniene, The Influence of Different Oregano Species on the Antioxidant Activity Determined Using HPLC Postcolumn DPPH Method and Anticancer Activity of Carvacrol and Rosmarinic Acid, Biomed Res Int, 2017, 2017, 1681392.

5- M. R. Morshedloo, H. Mumivand, L. E. Craker, F. Maggi, Chemical composition and antioxidant activity of essential oils in Origanum vulgare subsp. gracile at different phenological stages and plant parts, J Food Process Preserv, 2018, 42, $1-8$.

6- N. Aligiannis, E. Kalpoutzakis, S. Mitaku, I. B. Chinou, Composition and antimicrobial activity of the essential oils of two Origanum species., $J$ Agric Food Chem, 2001, 49, 4168-4170.

7- M. Skoula and J. B. Harborne, The taxonomy and chemistry of Origanum, Oregano: the Genera Origanum and Lippia,Taylor and Francis, 2002, 65-108.

8- F. Sozmen, B. Uysal, E O. Kose, O. Aktaş, I. Cinbilgel, B.S., Oksal, Extraction of the essential oil from endemic Origanum bilgeri 
P.H.Davis with two different methods: comparison of the oil composition and antibacterial activity. Chem.Bio divers, 2012,9(7), 1356-63.

9- K. Singletary, Oregano Overview of the Literature on Health Benefits, Nutr Today, 2010, 45(3), 129-138.

10-K. Carović-Stanko, M. Petek, M. Grdiša, J. Pintar, D. Bedeković, M. H. Ćustić, Z. Satovic, Medicinal plants of the family lamiaceae as functional foods-A review, Czech J Food Sci, 2016, 34, 377-390.

11-J. Bellakhdar, La pharmacopée marocaine traditionnelle. Médecine arabe ancienne et savoirs populaires, Paris - Rabat, Ibis Press -Eds Le Fennec, 1997, 1-764.

12-J. H. Ietswaart, A Taxonomic Revision of the Genus Origanum (Labiatae), Leiden University Press, LaHague, Netherland, 1980,4,1-160.

13-A. Amakran, M. Hamoudane, B. Ramdan, A. Lamarti, F. Pagniez, P. le Pape, M. Nhiri, Antifungal activity of the essential oil of origanum elongatum on candida, aspergillus and rhizopus species, J Mycol Med, 2014, 24, e78.

14-H. Ramzi, M. R. Ismaili, M. Aberchane, S. Zaanoun, Chemical characterization and acaricidal activity of Thymus satureioides C. \& B. and Origanum elongatum E. \& M. (Lamiaceae) essential oils against Varroa destructor Anderson \& Trueman (Acari: Varroidae), Ind Crops Prod, 2017, 108(1), 201-207.

15-N. E. L. Moussaoui, G. Sanchez, E. O. Khay, M. Idaomar, A. I. B. N. Mansour, J. Abrini, M. N. EL Moussaoui, G. Sanchez, Antibacterial and antiviral activities of essential oils of northern Moroccan plants, Br Biotechnol J, 2013, 3(3), 318-331.

16-A. Joshi, M. Bhobe, A. Sattarkar, Phytochemical investigation of the roots of Grewia microcos Linn. J. Chem. Pharm. Res, 2013,5(3), 80-87.

17-J. Bruneton, Les tanins, Parmacognosie Phytochimie- Plantes médicinales, Paris (France), Éditions Tec \& Doc et médicales internationales, 2009, 369-404

18-A. A. Dehpour, M. A. Ibrahimzadeh, N. seyed Fazel and N. Seyed Mohammad, Grasas Y Aceites, 2009,60(4), 405-412.

19-M. Atanasova, F. Ribarova, Phénols et flavonoïdes totaux dans les extraits secs des feuilles des bouleaux argentés bulgares (Betula pendula), Rev Génie Ind, 2009, 4, 21-25.

20-F. Nikhat, E.V.S. Subhramanyam, D. Satynarayana, Isolation Characterization and screening of Antioxidant activity of the Roots of Syzygium cuminii (L) skeel, Asian J. Research Chem., 2009, 2(2),218-22.

21-M. ZovkoKoncic, D. Kremer, K. Karlovic, I. Kosalec, Evaluation of antioxidant activities and phenolic content of Berberis vulgaris L. and
Berberis croatica Horvat, Food and Che. Tox., 2010,48(8),2176-2180.

22- A. C. Rana, B. Gulliya, Chemistry and pharmacology of flavonoids-a review, Indian $J$ Pharm Educ Res, 2019, 53(1), 8-20.

23-J. M. Geleijnse, P. C. H. Hollman, Flavonoids and cardiovascular health: Which compounds, what mechanisms?, Am J Clin Nutr, 2008, 88(1), 12-13.

24-S.A. Jassim, M.A Naji, Novel antiviral agents : A medicinal plant perspective. Appl Microbiol, 2003,95(3),412-427.

25-K. S. De Lira Mota, G. E. N. Dias, M. E. F. Pinto, Â. Luiz-Ferreira, A. R. M. Souza-Brito, C. A. Hiruma-Lima, J. M. Barbosa-Filho, L. M. Batista, Flavonoids with gastroprotective activity, Molecules, 2009, 14(3), 979-1012.

26- M. Fernández, J. Caballero, A. Morales Helguera, E. A. Castro, M.P. González, Quantitative structure-activity relationship to predict differential inhibition of aldose reductase by flavonoid compounds. Bio org Med Chem, 2005, 13(9),3269-77.

27-A. Ren, W. Zhang, H. G. Thomas, A. Barish, S. Berry, J. S. Kiel, A. P. Naren, A tannic acidbased medical food, cesinex $\AA$, exhibits broadspectrum antidiarrheal properties: A mechanistic and clinical study, Dig Dis Sci, 2012, 57, 99-108.

28-M. Biaye, Actions pharmacologiques des tanins. Thèse d'état en pharmacie sous la direction professeur Bassene, Dakar, Université Cheikh Diop de Dakar faculté de médecine, de pharmacie et d'odonto-stomatologie département de pharmacie, 2002, 1-60.

29-E. Sieniawska, Activities of Tannins from in Vitro Studies to Clinical Trials. Natural Product Communicat., 2015,10(11), 1877-1884.

30-H. Oualili, H. Rchid, R. Nmila, Phytochemical Screening and Antioxidant Activity of : Origanum elongatum and Cupressus atlantica Two Endemic Plants of Morocco, Int J Pharmacogn Phytochem Res, 2018, 10(5), 196-200.

31-Lahlou M. Potential of Origanum compactum as a cercaricide in Morocco. Ann Trop Med Parasitol, 2002, 96(6),587-93

32-P. Prerna, N. Vasudeva, Origanum majorana L. -Phyto-pharmacological review, Indian J Nat Prod Resour, 2015, 6(4), 261-267.

33-B. Douhri, M. Idaomar, N. Skali Senhaji, A. Ennabili, J. Abrini, Hepatoprotective Effect of Origanum elongatum against Carbon Tetrachloride (CCl4) Induced Toxicity in Rats, European J Med Plants, 2014, 4(1), 14-28.

34-A. Bouyahya, J. Abrini, Y. Bakri, N. Dakka, Screening phytochimique et évaluation de l'activité antioxydante et antibactérienne des extraits d'Origanum compactum, Phytotherapie, 2017, 15(6), 379-383.

35-H. Zieliński, H. Kozłowska, Antioxidant activity and total phenolics in selected cereal grains and 
their different morphological fractions, J Agric Food Chem, 2000, 48(6), 2008-2016.

36-F. El Babili, J. Bouajila, J. P. Souchard, C. Bertrand, F. Bellvert, I. Fouraste, C. Moulis, A. Valentin, Oregano: Chemical analysis and evaluation of its antimalarial, antioxidant, and cytotoxic activities, J Food Sci, 2011, 76(3), 512-518.

37-E. Scholz, H. Rimpler, Proanthocyanidins from Krameria triandra, Root. Planta Med,1989,55(4),379-384.

38-S . D. Wei, H. C. Zhou, Y. M. Lin, Antioxidant activities of extract and fractions from the hypocotyls of the mangrove plant Kandelia candel, Int J of Mol Sci, 2010, 11(10), 4080-4093.

39-A. Munawar, S. Farhan, F. M. Anjum, M. Afzaal, T. Tufail, M. S. Bashir, A. Ishtiaq, H. Shahzad, H.A.R. Suleria, Natural polyphenols: An overview. Inte J of food pro, 2017, 20(8), 1689-1699.

40-S. Abdillah, R.M. Tambunan, Y. Farida, N.M.D. Sandhiutami, R.M. Dewi, Phytochemical screening and antimalarial activity of some plants traditionally used in Indonesia, Asian Pac J Trop Dis, 2015; 5(6), 454-7
41-A. Özkan, A. Erdoğan, A comparative evaluation of antioxidant and anticancer activity of essential oil from origanum onites (lamiaceae) and its two major phenolic components, Turkish J Biol, 2011, 35, 735-742.

42-H. J. D. Dorman, O. Bachmayer, M. Kosar, R. Hiltunen, Antioxidant Properties of Aqueous Extracts from Selected Lamiaceae Species Grown in Turkey, J Agric Food Chem, 2004, 52, 762-770.

43-E. P. Gutiérrez-Grijalva, M. A. Picos-Salas, N. Leyva-López, M. S. Criollo-Mendoza, G. Vazquez-Olivo, J. B. Heredia, Flavonoids and phenolic acids from Oregano: Occurrence, biological activity and health benefits, Plants, 2018, 7(1), 1-23.

44-D. Malešev, V. Kuntić, Investigation of metalflavonoid chelates and the determination of flavonoids via metal-flavonoid complexing reactions, J Serbian Chem Soc, 2007, 72, 921-939.

45-P. Siddhuraju, K. Becker, Antioxidant properties of various solvent extracts of total phenolic constituents from three different agroclimatic origins of drumstick tree (Moringa oleifera Lam.) leaves, J Agric Food Chem, 2003, 51(8), 2144-2155. 